\title{
Study of the Understanding of Gestural Communication in Children with Intellectual Disabilities in the Dynamics of Psychological Impact
}

\author{
Oksana V. Zashchirinskaia*
}

\author{
Department of Pedagogics and Pedagogical Psychology, Saint Petersburg State University, Saint \\ Petersburg, Russian Federation
}

\begin{abstract}
Objective: The purpose of the study is to investigate the specific features of non-verbal communication in children with intellectual disabilities in the dynamics of psychological impact.

Background: Gestures are one of the most important components of non-verbal communication. The development of non-verbal communication in children with intellectual disabilities contributes to their normal social adaptation.

Method: To study the current state and dynamics of the development of the ability to recognise and understand gestures in the process of psychological influence, factor analysis was used by the principal component method with the use of varimax rotation. To verify the applicability of factor analysis to the selected variables, the Kaiser-Meier-Olkin measure of sample adequacy and Bartlett's sphericity test were used.

Results: The data of the study showed that, depending on the level of intelligence or, more precisely, on the diagnosis given to the child, there are differences in the dynamics of the development of the components of non-verbal communication. Children with mild mental retardation display lower results than children with mixed specific disorders of psychological development and children with a normative level of intellectual development.
\end{abstract}

Conclusion: The results obtained in the process of this study can be applied in practice by teachers and psychologists when working with children with intellectual disabilities.

Keywords: Sign language, schoolchildren, psychology, pedagogy, communication skills.

\section{INTRODUCTION}

Non-verbal communication against the background of a decrease in intelligence turns out to be an earlier method of communication in conditions of dysontogenesis and, as a result, is more closely related to socialisation. Its mechanisms as a whole may be less correlated with the level of development of consciousness and personality [1]. Accordingly, purposeful work on the development of non-verbal communication will presumably allow for more successful socialisation of children with mild mental retardation, which in turn partially compensates for the intellectual impairment and reduces the risks of their social isolation [2]. Non-verbal communication is an integral part of the communication process. It becomes a means of compensation in the presence of mental retardation in a child since it occurs phylogenetically earlier than verbal communication [3]. Non-verbal communication of children with mild mental retardation in comparison with normatively developing peers and with mixed specific psychological disorders is described by a lower level of development of cognitive, emotional-personal, and behavioural components [4].

*Address correspondence to this author at the Saint Petersburg State University, Saint Petersburg, Russian Federation; Tel: +7812 36366 33; E-mail: zashchirinskaia5112@ubogazici.in
Furthermore, the most pronounced is the underdevelopment of the cognitive component, which is associated with the specific features of impaired intelligence.

Gestures are one of the most important components of non-verbal communication. In many countries, gestures are classified into two types [5]. The first type is the sign language of deaf people. This type is primary and does not depend on the spoken language. This type has its individual grammar, a system of inflexion, which differs from the spoken language; there are also certain dialectal differences. The second type of manual signs is sign systems [6]. Sign systems are secondary; they convey verbal speech literally. Signal systems that correspond to spoken language are often used to work with hearing people who have certain impairments in communication skills. Gestures and speech are used when using alternative methods of communication simultaneously due to the fact that gesture systems are based on verbal speech [7]. Gestures help children visualise words; they help the child memorise them better. Also, gestures help the child understand the meaning of words. All existing gestures can be divided into several groups [8]

The first group is symbolic social gestures and movements. The child can learn this group of gestures 
with the help of situational business communication. For example, with the help of the following words and gestures: "Yes", "No", "Come here", "Hello", "Goodbye", and many others. The second group includes additional social gestures. This group of gestures imitates simple object-related actions, for example, while eating, playing, washing, travelling, while preparing for bed.

The next group includes gestures of a descriptive nature that convey certain characteristic properties and traits that are inherent in a particular object, for example, gestures showing animals, books, cars, planes, trains, or certain gestures that describe objects, for example, small, large, tall, low, etc. [9].

Gestures have advantages and disadvantages. The advantages include the ability to constantly use the hands, unlike other special devices, sign language is visual, parents or teachers can help the child with their own hands, and sign language is accompanied by eye contact [10]. The disadvantages include limited communication of children with motor dysfunctions, and some gestures may not be understandable to everyone, gestures disappear immediately after their "pronunciation", the child also needs to remember all the gestures and be capable of reproducing them [11].

\section{METHODOLOGY}

Diagnostic examination of each child was carried out with the obligatory consideration of its individual characteristics. Thus, in the course of the study, normally developing children gave faster and more complete answers to the questions asked. The total time spent on the diagnostic procedure varied from 30 to 45 minutes. Peers with intellectual disabilities had to spend much more time looking for an answer; it was more difficult for them to formulate speech statements during the diagnostic examination. They spent additional time perceiving and comprehending the diagnostic material, which was within the individual range of time indicators from 45 to 60 minutes or more, considering the need for rest breaks in such children, based on their fatigue and impaired concentration. These features of the diagnostic procedure persisted with the repeated presentation of subtests after the classes under the programme of psychological influence on the development of non-verbal communication in children with intellectual disabilities.
This version of the study of assessing the level of development of non-verbal communication was performed directly during interaction with children. The diagnostic procedure was performed with each child individually with the use of special demonstration cards depicting people showing various gestures, and the result of the examination was recorded by a psychologist in a special protocol. For the correct conduct of the study, the psychologist needed to establish a trusting contact with the child, offering it to take a look at several interesting pictures. During the examination, the child's biographical data were indicated in detail, and pictures with questions were presented strictly in the order specified in the protocol.

The images were presented in turn, and those that had already been answered were removed out of the child's sight. During the survey, the response time was assessed, and it was not recommended to rush the child or prompt it to answer questions. All the child's responses and other statements that occurred during the conversation were carefully recorded, as well as all additional information about the observed behaviour of the examined child. When showing the images, the child was asked questions about what it sees in the picture, what this gesture means, whether the child uses it and in what situations, how the child and adults relate to this gesture. According to the results of the diagnosis, the psychologist gave a score from 0 to 4 for each picture, where the score of 0 corresponded to the adequate understanding of the gesture and the correctness of its use. This version of the diagnostic study was used since gestures constitute one of the key components of non-verbal communication. This approach allowed not only to conduct a qualitative study of this component of non-verbal communication but also to translate qualitative indicators into quantitative ones through the use of the developed measuring scale.

To process and analyse the data obtained, various methods of mathematical and statistical processing of indicators of communication development were used: factorial and variance analyses. The data obtained were systematised and presented in the form of graphs, tables, and figures. For theoretical consideration of information, the scientific literature on the subject matter was analysed. Scientific publications of foreign authors on the subject of non-verbal and gesture communication in children with intellectual disabilities were considered. 


\section{RESULTS}

\section{The Study of Understanding Gestural Communi- cation}

To study the current state and dynamics of the development of the ability to recognise and understand gestures in the process of psychological influence, factor analysis was used by the principal component method with the use of varimax rotation. To verify the applicability of factor analysis to the selected variables, the Kaiser-Meier-Olkin measure of sampling adequacy and Bartlett's sphericity test were used. The KaiserMayer-Olkin measure of selective adequacy and the Bartlett test are presented in Table 1.

Table 1: Kaiser-Meyer-Olkin Measure of Selective Adequacy and Bartlett Test

\begin{tabular}{|c|c|c|}
\hline \multicolumn{2}{|c|}{ Criterion } & Value \\
\hline \multicolumn{2}{|c|}{ Kaiser-Meyer-Olkin measure of selective adequacy } & 0.902 \\
\hline \multirow{3}{*}{$\begin{array}{l}\text { Bartlett's criterion for } \\
\text { sphericity }\end{array}$} & Approximate $x^{2}$ & $4,453.307$ \\
\hline & Statistical properties & 496 \\
\hline & p-value & $<0.001$ \\
\hline
\end{tabular}

The criterion for the adequacy of the Kaiser-MeyerOlkin sample is a value that describes the degree of applicability of factor analysis to a given sample. The Kaiser-Meyer-Olkin measure of sample adequacy = 0.902 - the data are certainly adequate for the application of factor analysis. Bartlett's sphericity criterion is a multidimensional normality criterion for the distribution of variables. Apart from normality, the criterion checks whether the correlations differ from 0 . A p-value less than 0.05 indicates that the data is quite acceptable for Cattell factor analysis, according to which the number of factors is determined by the inflexion point on the graph before it reaches a gentle straight line after a sharp decline of eigenvalues, eigenvalues of the selected factors are greater than 3 . The scree plot is presented in Figure 1.

The 3 highlighted factors explain $74.69 \%$ of the total variance of the analysed indicators. The contribution of factors to the total variance of the studied indicators is presented in Table 2. The graphic structure of the factors is presented in Figure $\mathbf{2}$.

For the studied "factor 1", the load was distributed on the indicators of response time to cards: greeting
(0.746), request (0.768), prohibition (0.955), demonstration $(0.957)$, praise $(0.935)$, consideration (0.952), pointing gesture $(0.951)$, concealing gesture (0.959), offensive gesture (0.960), anger (0.931), refusal (0.935), threat $(0.960)$, fun (0.939), reluctance (0.939), punishment (0.953), mocking gesture (0.909). The contribution of this factor to the total variance of the initial traits was $44.3 \%$. Based on the variables included in this factor, reflecting the cognitive activity of students, aimed at assessing the object, this factor is called "The cognitive component of non-verbal communication".

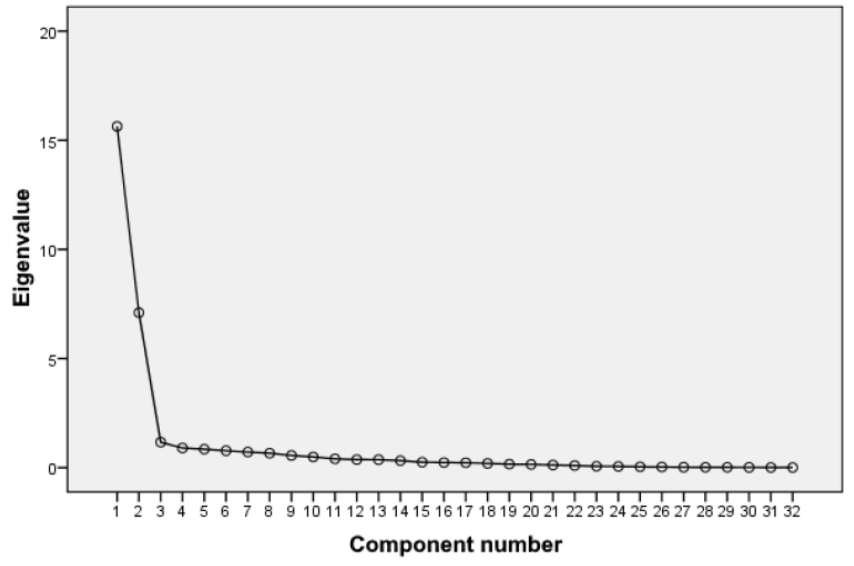

Figure 1: Scree plot.

Table 2: Contribution of Factors to the Total Variance of the Indicators Understudy

\begin{tabular}{|c|c|c|}
\hline \multirow{2}{*}{ Factor } & \multicolumn{2}{|c|}{ Sums of squares of rotational loads } \\
\cline { 2 - 3 } & \% variance & Cumulative \% \\
\hline \hline 1 & 44.30 & 44.30 \\
\hline 2 & 24.60 & 68.90 \\
\hline 3 & 5.79 & 74.69 \\
\hline
\end{tabular}

In the studied "factor 2", the load was distributed on the following gestures: prohibition (0.739), demonstration $(0.654)$, praise $(0.766)$, consideration (0.760), concealing gesture (0.853), anger (0.775), refusal $(0.710)$, threat $(0.786)$, fun $(0.807)$, reluctance $(0.761)$, punishment $(0.725)$, teasing gesture $(0.807)$. The contribution of this factor to the total variance of the initial traits was $24.6 \%$. The name of the factor: "The emotional and personal component of non-verbal communication". This component reflects the inextricable link between emotions and personal behaviour in children. 


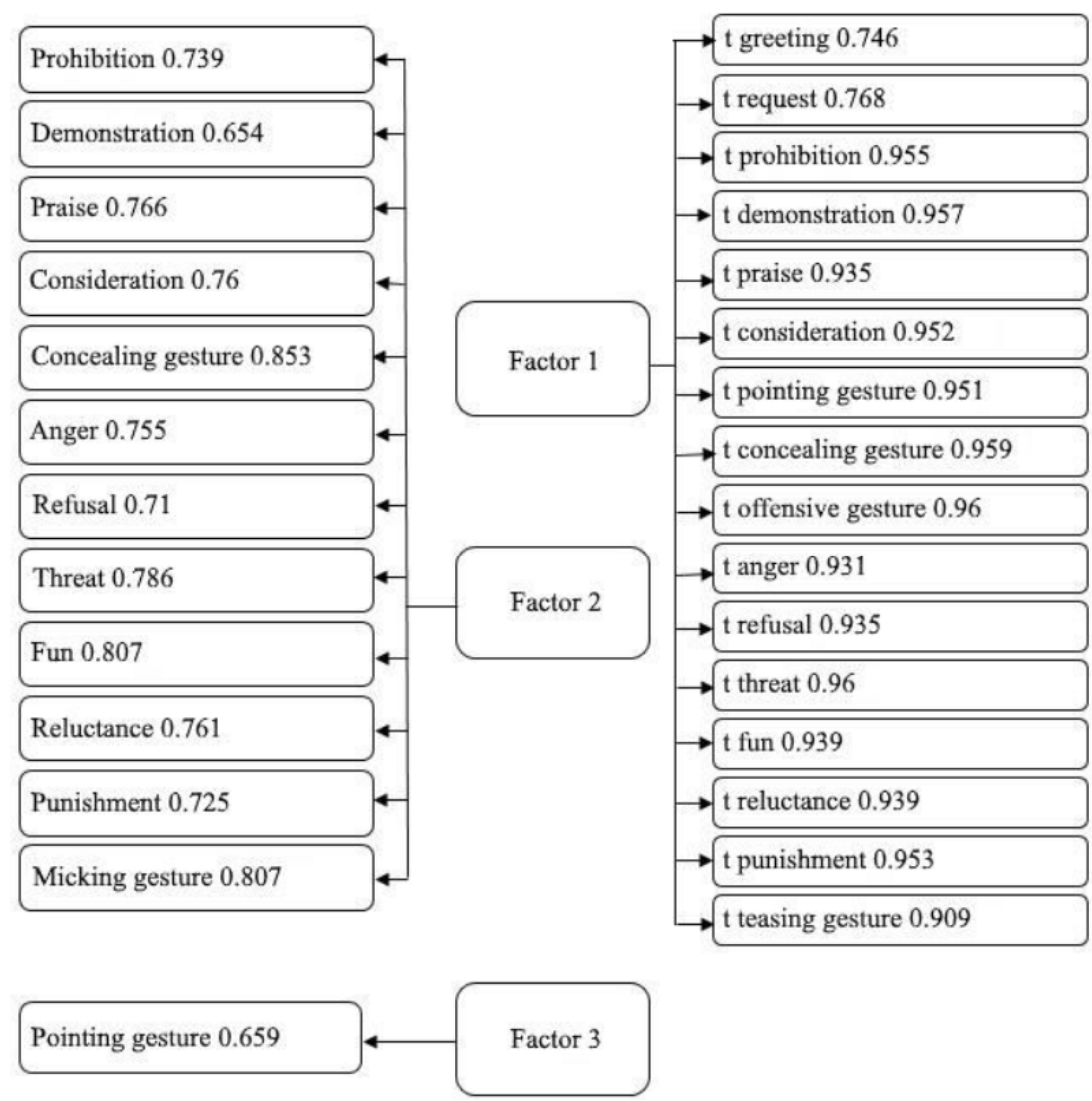

Figure 2: The factor structure of the results of the experimental psychological study of gestures.

For the studied "factor 3", the load was distributed to the following indicator: pointing gesture $(0.659)$. The contribution of this factor to the total variance of the initial traits was $5.8 \%$. This factor is called the "Behavioural component of non-verbal communication", since this gesture is primarily a behavioural response aimed at interacting with other people.

Based on the obtained factor estimates of the level of development of the components of non-verbal communication, a comparative analysis was performed, which allowed dividing the subjects into groups depending on the diagnosis. Considering the correction for multiple comparisons, the boundary probability of a type I error was set at the level $\alpha=$ 0.017 . The average values of the compared components of non-verbal communication with the use of the example of studying the understanding of gestures are presented in Figure 3.

As suggested by the above diagram (a higher score corresponds to a lower level of development), the level of development of each component has a minimum

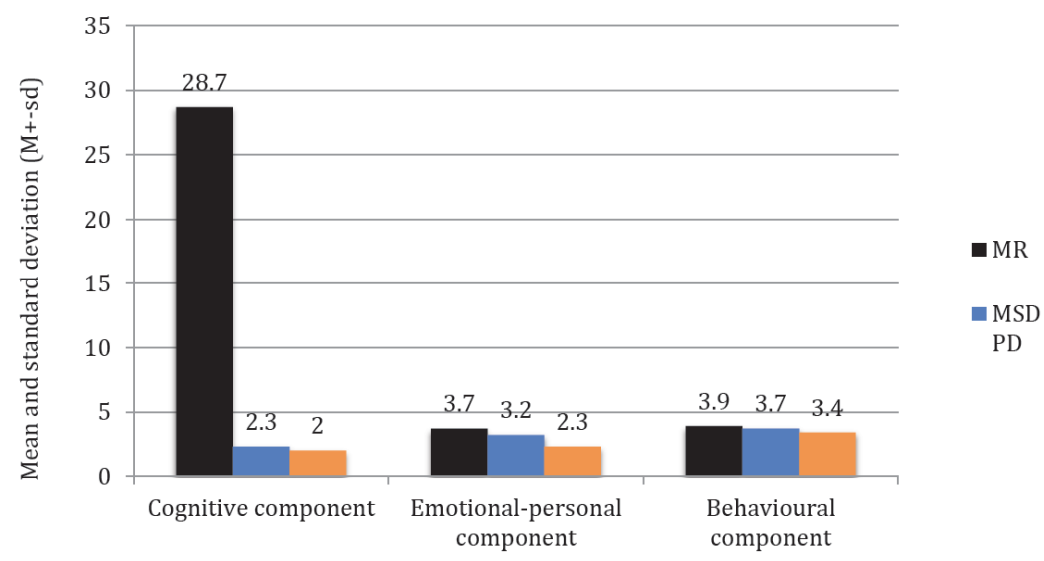

Figure 3: Average values of the components of gesture communication in children depending on the diagnosis. 
Table 3: Comparative Characteristics of the Components of Non-Verbal Communication in Children

\begin{tabular}{|c|c|c|c|}
\hline & $\begin{array}{l}\text { Group } 1(M R) \\
\quad(M \pm s d)\end{array}$ & 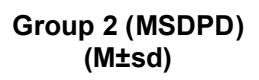 & $\begin{array}{c}\text { Group } 3 \text { (ND) } \\
\quad(\mathrm{M} \pm \mathrm{sd})\end{array}$ \\
\hline Cognitive component & $28.74 \pm 16.87^{*}$ & $2.32 \pm 2.8$ & $2.04 \pm 1.8^{* * *}$ \\
\hline Emotional-personal component & $3.75 \pm 0.32^{*}$ & $3.22 \pm 0.66^{\star *}$ & $2.29 \pm 0.82^{* \star *}$ \\
\hline Behavioural component & $3.94 \pm 0.24$ & $3.67 \pm 0.84$ & $3.37 \pm 1.22$ \\
\hline
\end{tabular}

Notes: * - statistically significant differences in groups 1 and $2(p<0.017)$

** - statistically significant differences in groups 2 and $3(p<0.017)$.

*** — statistically significant differences in groups 1 and $3(p<0.017)$.

value in the group of children with a normative level of intellectual development (hereinafter on all diagrams "ND"), slightly higher - in the group of children with mixed specific disorders of psychological development (hereinafter on all diagrams - "MSDPD"), and maximum - in the group of children with mild mental retardation (hereinafter on all diagrams - "MR").

At the qualitative level, emotional-personal and behavioural components in the group with mild mental retardation correspond to the assessment "no response, inadequate interpretation of people's actions, justification of the wrong naming of the gesture".

In the group of subjects with mixed specific disorders of psychological development, at the qualitative level, the behavioural component corresponds to the assessment "no response, inadequate interpretation of people's actions, a justification for the wrong naming of the gesture", and the emotional-personal component corresponds to "general response, oral description of the image in the picture. Therewith, the child does not pay attention to the gesture. The interpretation of gestures or movements of people is conveyed in the form of their direct speech. Shows gesture unassisted".

In the group of children with a normative level of intellectual development, who study in the first grade, the behavioural component at the qualitative level corresponds to the assessment "general response, oral description of the image in the picture. Therewith, the child does not pay attention to the gesture. The interpretation of gestures or movements of people is conveyed in the form of their direct speech. Shows gesture unassisted." The emotional-personal component includes the assessment "the description of the gesture is replaced by the correct description of the situation or the actions of the people in the picture. The person's gesture is definitely not named. Justification of understanding the gesture in the form of separate words or unstructured statements".
As the table below suggests, the level of development of the emotional-personal component is statistically significant $(p<0.017)$ different in all groups of the surveyed, decreasing in the continuum from a group of children with mild mental retardation to a group of children with a normative level of intellectual development. Comparative characteristics of the components of non-verbal communication in children are presented in Table 3 . The best indicators are observed in the group of normatively developing children, low results - in the group with mild mental retardation. In the group with mixed specific disorders of mental development, the severity of the emotionalpersonal component takes an intermediate position.

The cognitive component is also statistically ( $p$ $<0.017$ ) lower in the group of those surveyed with mild mental retardation compared to children with mixed specific disorders of psychological development and normatively developing children. Thus, the surveyed children with mild mental retardation give statistically significantly longer answers to the questions posed; they are described by prolonged reflection and the search for the correct answer. To study the dynamics of changes in the components of non-verbal communication in relation to recognition and understanding of gestures after psychological impact, analysis of variance with repeated measures was used. The results of the dynamics of changes in the groups are presented in Figures 4, 5, and 6 .

As the diagram suggests, the level of development of the cognitive component in all groups of the surveyed increased. Thus, in the group of children with mild mental retardation, the average response time decreased by $51 \%$, in the group of those surveyed with mixed specific disorders of psychological development - by $51.3 \%$, in the group of children with a standard level of intelligence development - by $76 \%$.

As the above diagram suggests, the level of development of the emotional-personal component of 


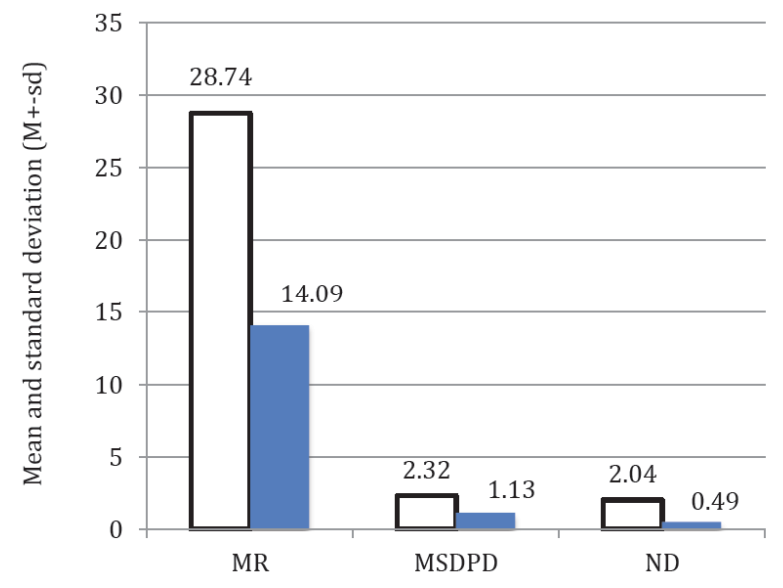

Figure 4: Dynamics of changes in the cognitive component in the study groups.

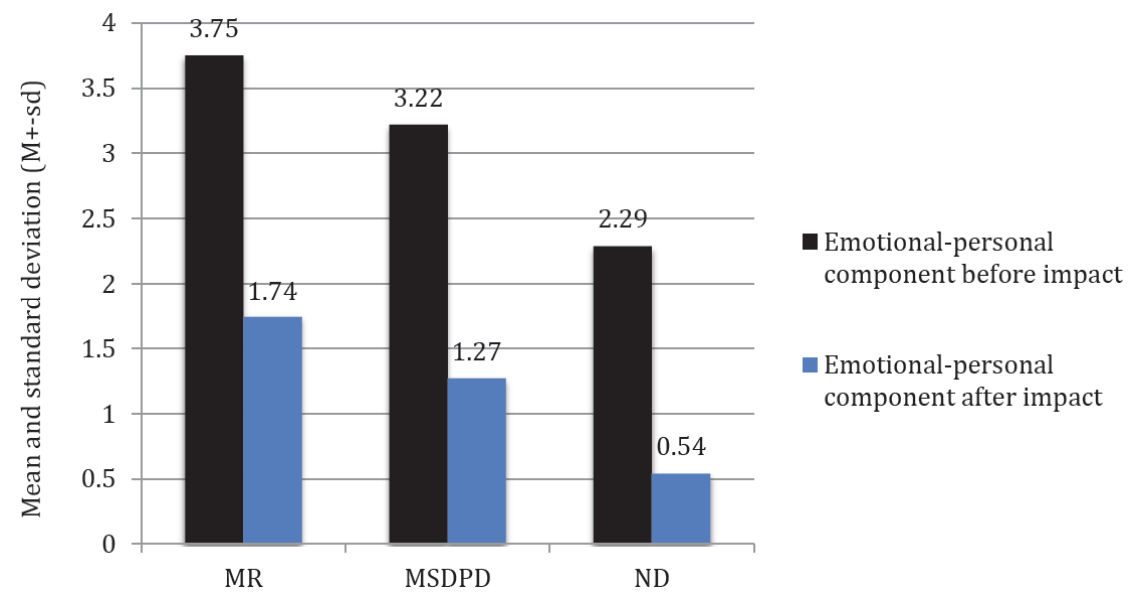

Figure 5: Dynamics of changes in the emotional and personal component in the surveyed groups.

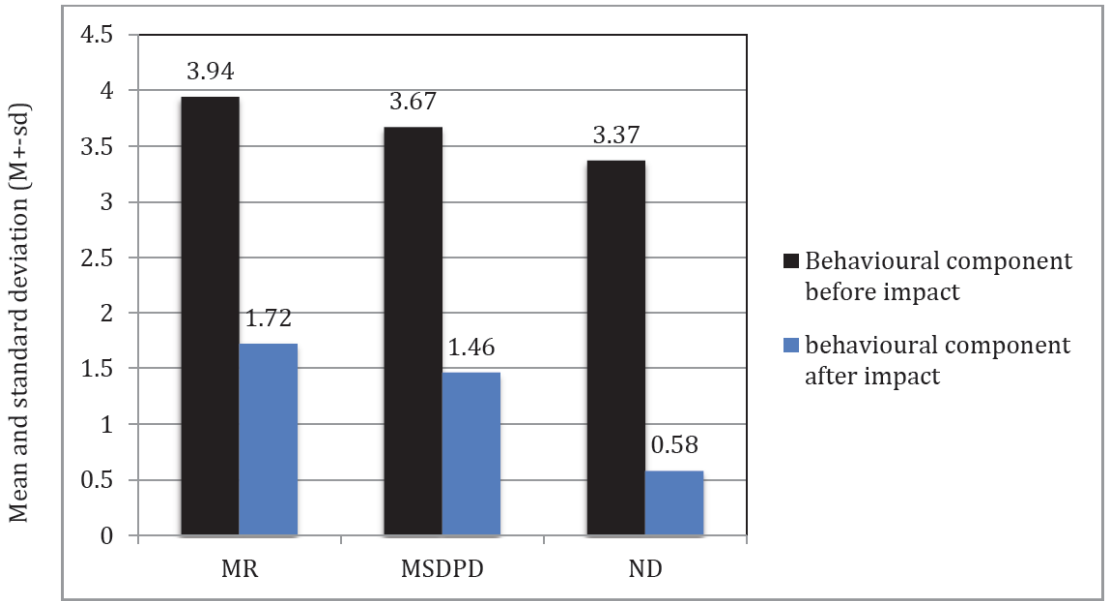

Figure 6: Dynamics of changes in the behavioural component in the groups of examined children.

non-verbal communication in all groups of the surveyed increased. The quality of answers in the group of those surveyed with mild mental retardation improved by $53.6 \%$, in the group of those surveyed with mixed specific disorders of psychological development by
$60.6 \%$, in the group of children with a normative level of intelligence development - by $76.4 \%$.

In the above graph (Figure 6), the level of development of the behavioural component of non- 
Table 4: Dynamics of Changes in the Surveyed Groups

\begin{tabular}{|c|c|c|c|}
\hline Component & $\begin{array}{c}\text { Group } 1 \text { (MR) } \\
\quad(M \pm s d)\end{array}$ & 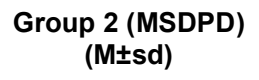 & $\begin{array}{c}\text { Group } 3 \text { (ND) } \\
(\mathrm{M} \pm \mathrm{sd})\end{array}$ \\
\hline Cognitive component before impact & $28.74 \pm 16.87$ & $2.32 \pm 2.80$ & $2.04 \pm 1.80$ \\
\hline Cognitive component after impact & $14.09 \pm 7.60^{*}$ & $1.13 \pm 1.07^{*}$ & $0.49 \pm 0.72^{*}$ \\
\hline Emotional-personal component before impact & $3.75 \pm 0.32$ & $3.22 \pm 0.66$ & $2.29 \pm 0.82$ \\
\hline Emotional-personal component after impact & $1.74 \pm 0.81^{*}$ & $1.27 \pm 0.36^{*}$ & $0.54 \pm 0.50^{*}$ \\
\hline Behavioural component before impact & $3.94 \pm 0.24$ & $3.67 \pm 0.84$ & $3.37 \pm 1.22$ \\
\hline Behavioural component after impact & $1.72 \pm 0.96^{*}$ & $1.46 \pm 0.88^{*}$ & $0.58 \pm 0.59^{*}$ \\
\hline
\end{tabular}

Notes: * - differences are statistically significant $(p<0.05)$ before and after psychological impact.

verbal communication increased in all groups. In the group with mild mental retardation, the quality of answers improved by $56.3 \%$, in the group with mixed specific disorders of psychological development - by $60.2 \%$, in the group of children with a standard level of intelligence development - by $82.8 \%$.

According to the results of comparative analysis, the dynamics of changes in all groups is statistically significant. The dynamics of changes in the groups studied are presented in Table 4.

Psychological impact statistically $(p \quad<0.05)$ improved the main components of non-verbal communication (cognitive, emotional-personal, behavioural) (see Table 4). The most pronounced positive dynamics is noted in the group of children with a normative level of intellectual development, less pronounced in the group of children with mild mental retardation. The results of a comparative analysis after psychological impact are presented in Table $\mathbf{5}$.

After psychological influence, the level of expression of the main components of non-verbal communication in the continuum from mild mental retardation to the conditionally normative level of intellectual development remained (see Table 5). Statistically significant $(p<0.017)$ differences in the level of severity of the behavioural component between children with mixed specific disorders of psychological development and normatively developing children were added to the existing differences that were identified at the summative stage of the study.

Thus, to get a general idea of the results obtained in two groups (a group of children of primary school age with a normative level of intellectual development and a group of children with intellectual disabilities) the parameters under study were compared with the use of the Student's t-test for independent samples.

The largest number of statistically significant differences is observed in the indicators obtained during the study of non-verbal communication of primary school children by a psychologist. Therewith, the reaction time indicators are statistically $(p<0.05)$ higher in children with intellectual disabilities, while the assessments reflecting the level of recognition, identification, and understanding of various gestures, on the contrary, are statistically higher in normatively developing children.

The least differences between the groups are observed in the assessments of children's non-verbal communication by parents. For them, in general, there is no difference in how their children communicate

Table 5: Comparative Characteristics of the Components of Non-Verbal Communication in Children after Psychological Impact

\begin{tabular}{|c|c|c|c|}
\hline & $\begin{array}{l}\text { Group } 1 \text { (MR) } \\
\quad(M \pm s d)\end{array}$ & 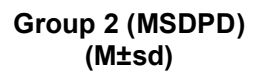 & $\begin{array}{c}\text { Group } 3 \text { (ND) } \\
(\mathrm{M} \pm \mathrm{sd})\end{array}$ \\
\hline Cognitive component & $14.09 \pm 7.60^{\star}$ & $1.13 \pm 1.07$ & $0.49 \pm 0.72^{\star * *}$ \\
\hline Emotional-personal component & $1.74 \pm 0.81^{*}$ & $1.27 \pm 0.36^{\star *}$ & $0.54 \pm 0.50^{* * *}$ \\
\hline Behavioural component & $1.72 \pm 0.96$ & $1.46 \pm 0.88^{* *}$ & $0.58 \pm 0.59^{* * *}$ \\
\hline
\end{tabular}

Notes: * - statistically significant differences in groups 1 and $2(p<0.017)$

** - statistically significant differences in groups 2 and $3(p<0.017)$.

*** — statistically significant differences in groups 1 and $3(p<0.017)$ 
depending on their diagnosis. Therewith, teachers, on the contrary, tend to notice differences in the manifestations of children's non-verbal communication, depending on the degree of decrease in their intelligence. They also indicate that it is more difficult for children with intellectual disabilities to understand and use various conventional gestures in communication.

The Study of Gestures in Communication Situations in Children with Intellectual Disabilities in the Dynamics of Psychological Impact

To study the current state and dynamics of the development of the ability to recognise and understand gestures in situations in the process of psychological impact, the factor analysis of the principal component method with the use of varimax rotation was used. To test the applicability of factor analysis to the selected variables, the Kaiser-Meyer-Olkin measure of sample adequacy and Bartlett's sphericity criterion are used. The Kaiser-Meyer-Olkin measure of selective adequacy and the Bartlett test are presented in Table 6.

Table 6: Kaiser-Meyer-Olkin Measure of Selective Adequacy and Bartlett Test

\begin{tabular}{|c|c|c|}
\hline \multicolumn{2}{|c|}{ Criterion } & Value \\
\hline \multicolumn{2}{|c|}{ Kaiser-Meyer-Olkin measure of selective adequacy } & 0.875 \\
\hline \multirow{3}{*}{$\begin{array}{l}\text { Bartlett's criterion for } \\
\text { sphericity }\end{array}$} & Approximate $x^{2}$ & $11,796.147$ \\
\hline & Statistical properties & 2775 \\
\hline & $\mathrm{p}$-value & $<0.001$ \\
\hline
\end{tabular}

The criterion for the adequacy of the Kaiser-MeyerOlkin sample is a value that describes the degree of applicability of factor analysis to a given sample. The measure of the Kaiser-Meyer-Olkin sample adequacy is 0.875 - high adequacy of factor analysis for this sample. Bartlett's sphericity criterion is a multidimensional normality criterion for the distribution of variables. Apart from normality, the test verifies whether the correlations differ from 0 . A p-value of less than 0.05 indicates that the data is acceptable for factor analysis.

Four factors were identified based on the interpretation of their content, the Cattell criterion, according to which the number of factors is determined by the inflexion point on the graph before it reaches a gentle straight line after a sharp decline in eigenvalues, the eigenvalues of the selected factors are greater than 1. The scree plot is presented in Figure 7.

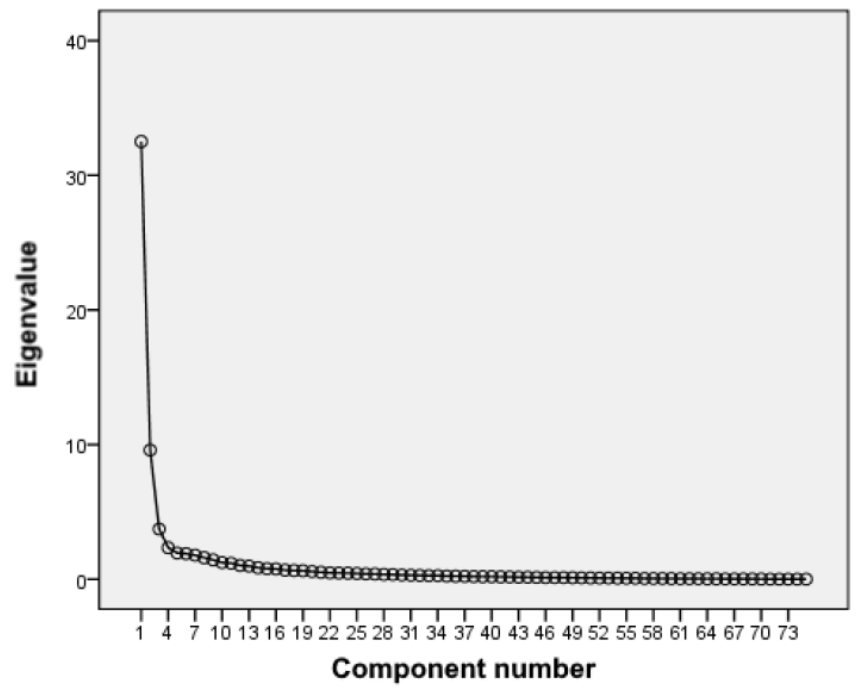

Figure 7: Scree plot.

Four highlighted factors explain $64.221 \%$ of the total variance of the analysed indicators. The contribution of factors to the total variance of the studied indicators is presented in Table 7. The graphical structure of the factors is presented in Figure 8.

Table 7: Contribution of Factors to the Total Variance of the Studied Indicators

\begin{tabular}{|c|c|c|}
\hline \multirow{2}{*}{ Factor } & \multicolumn{2}{|c|}{ Sums of squares of rotational loads } \\
\cline { 2 - 3 } & \% variance & Cumulative \% \\
\hline \hline 1 & 23.68 & 23.68 \\
\hline 2 & 19.28 & 42.97 \\
\hline 3 & 12.49 & 55.46 \\
\hline 4 & 8.764 & 64.22 \\
\hline
\end{tabular}

For the studied "factor 1 ", the load was divided into the following indicators: PD invitation (0.758), R prohibition (0.723), PD dismay (0.726), PD interest (0.747), R interest (0.724), PD joy (0.705), PD delight (0.782), R delight (0.746), PD length demonstration (0.746), PD volume demonstration (0.788). The contribution of this factor to the total variance of the initial traits was $23.68 \%$. The name of the factor: "The emotional-personal component of non-verbal communication." This component reflects the inextricable link between emotions and personal behaviour in children. 


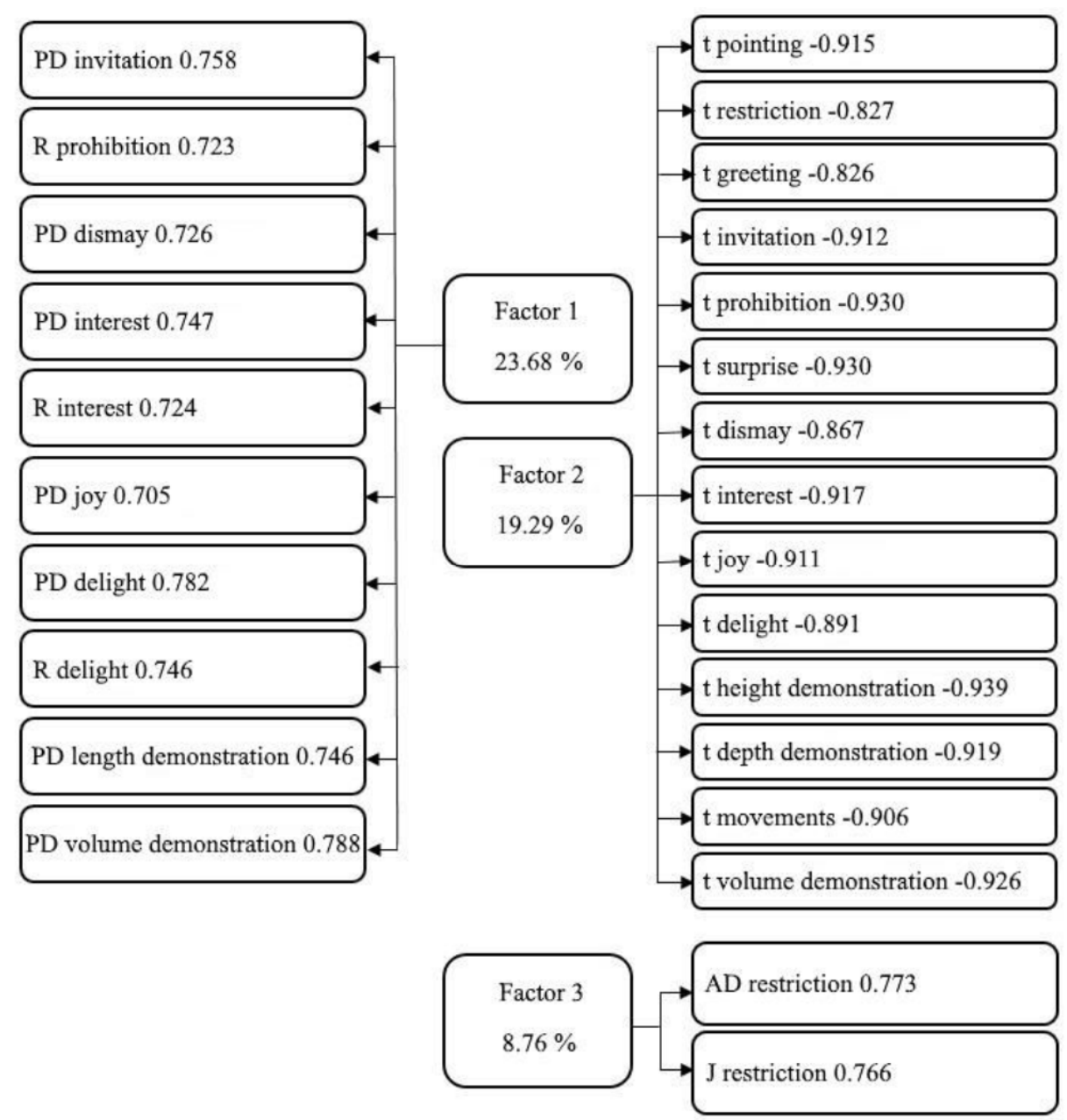

Figure 8: The factor structure of the results of the experimental psychological study of gestures in a situation.

List of abbreviations: PD - picture description; AD - action description; $\mathrm{R}$ - recognition; $\mathrm{J}$ - justification.

For the studied "factor 2", the load was distributed on the response time indicators for the following cards: indication (-0.915), restriction $(-0.827)$, greeting ($0.826)$, invitation $(-0.912)$, prohibition $(-0.930)$, surprise $(-0.930)$, dismay $(-0.867)$, interest $(-0.917)$, joy $(-0.911)$, delight $(-0.891)$, height demonstration $(-0.939)$, depth demonstration (-0.919), movement $(-0.906)$, length demonstration (- 0.909), volume demonstration (0.926). The contribution of this factor to the total variance of the initial traits was $19.29 \%$. This factor is called the "Cognitive component of non-verbal communication", since it included gestures associated with the cognitive activity of students aimed at assessing the object.

For the studied "factor 3", the load was divided into the following indicators: $A D$ restriction (0.773), J restriction (0.766). The contribution of this factor to the total variance of the initial traits was $8.76 \%$. This factor is called "The behavioural component of non-verbal communication", since this gesture is primarily a behavioural response aimed at interacting with other people. After obtaining estimates of the values of factors, a comparative analysis of the obtained estimates of the level of development of the considered components of non-verbal communication was performed with the use of analysis of variance. Considering the Bonferroni correction for multiple comparisons, the probability of a type I error was $\alpha=$ 0.017 . The average values of the components of nonverbal communication are presented in Figure $\mathbf{9}$.

The diagram above suggests that depending on the diagnosis, the assessments of the level of the actual development of non-verbal communication components qualitatively differ. Upon answering in the process of analysing pictures on the presented visual stimuli, children with mild mental retardation predominantly gave the following answer options: no response or an absurd interpretation; wrong interpretation; listing of what was seen in the picture. In children with mixed specific disorders of psychological development, the 


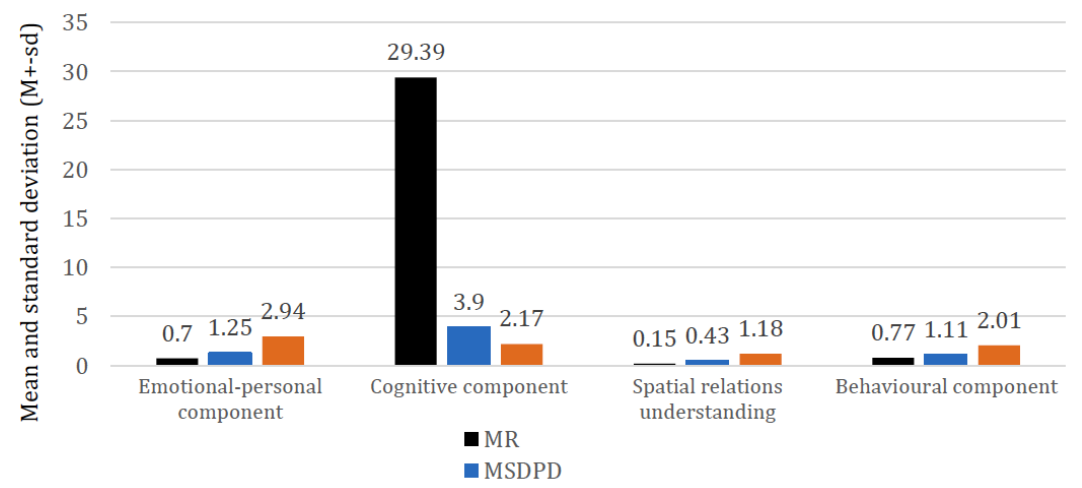

Figure 9: Average values of the components of non-verbal communication in the surveyed first-grade students.

Table 8: Comparative Characteristics of the Components of Non-Verbal Communication in Children

\begin{tabular}{|c|c|c|c|}
\hline & $\begin{array}{l}\text { Group } 1(M R) \\
\quad(M \pm s d)\end{array}$ & $\begin{array}{c}\text { Group } 2 \text { (MSDPD) } \\
(M \pm s d)\end{array}$ & $\begin{array}{c}\text { Group } 3 \text { (ND) } \\
(M \pm s d)\end{array}$ \\
\hline Emotional-personal component & $0.7 \pm 0.84^{*}$ & $1.25 \pm 0.74^{\star *}$ & $2.94 \pm 0.84^{\star * *}$ \\
\hline Cognitive component & $29.39 \pm 21.81^{*}$ & $3.9 \pm 3.98^{\star *}$ & $2.17 \pm 1.87^{* * *}$ \\
\hline Behavioural component & $0.77 \pm 1.21$ & $1.11 \pm 1.23^{\star *}$ & $2.01 \pm 1.24^{\star \star *}$ \\
\hline
\end{tabular}

Notes: * - statistically significant differences in groups 1 and $2(p<0.017)$

${ }^{* *}$ - statistically significant differences in groups 2 and $3(p<0.017)$.

$* * *$ statistically significant differences in groups 1 and $3(p<0.017)$

following answers prevailed: wrong interpretation or general answer; correct re-enumeration of people's actions, ignoring gestures, the context of the situation (Table 8).

In children with a normative level of intellectual development, responses of a general nature were mainly noted, which can be attributed to a variety of situations of non-verbal communication and outside the context of non-verbal communication. They had errors in the interpretation of the actions of one of the communication partners. Comprehension of the gesture was demonstrated in the form of single words or unstructured utterances.

As the table above indicates, children with a normative level of intellectual development have statistically significantly $(p<0.017)$ higher indicators of the development of non-verbal communication components when compared with groups of children with mild mental retardation and with mixed specific disorders of psychological development.

Groups of children with mild mental retardation and with mixed specific disorders of psychological development differ only in the level of severity of emotional-personal and cognitive components. They also have an equally insufficiently developed understanding of prohibitions, due to which impulsive behaviour is noted, as well as ignorance of educational influences. At the next stage, the obtained estimates of the components of non-verbal communication before and after the psychological impact were compared. The results comparing the dynamics of changes in groups are presented in Figures 10-12.

As the above diagram suggests, the level of development of the emotional-personal component of non-verbal communication increased in all groups. The quality of answers in the group with mild mental retardation improved 4.5 times, in the group with mixed specific disorders of psychological development -2.5 times, in the group of normatively developing children by $35.7 \%$.

The level of development of the cognitive component in the groups with mild mental retardation and normatively developing children increased, in the group with mixed specific disorders of psychological development it slightly decreased (see Figure 11). Thus, in the group with mild mental retardation, the average response time decreased by $68.15 \%$, in the group of normatively developing children by $78.9 \%$, in the group with mixed specific disorders of psychological development the response time increased by $11 \%$, which may be due to with their characteristic fatigue-especially given that this 


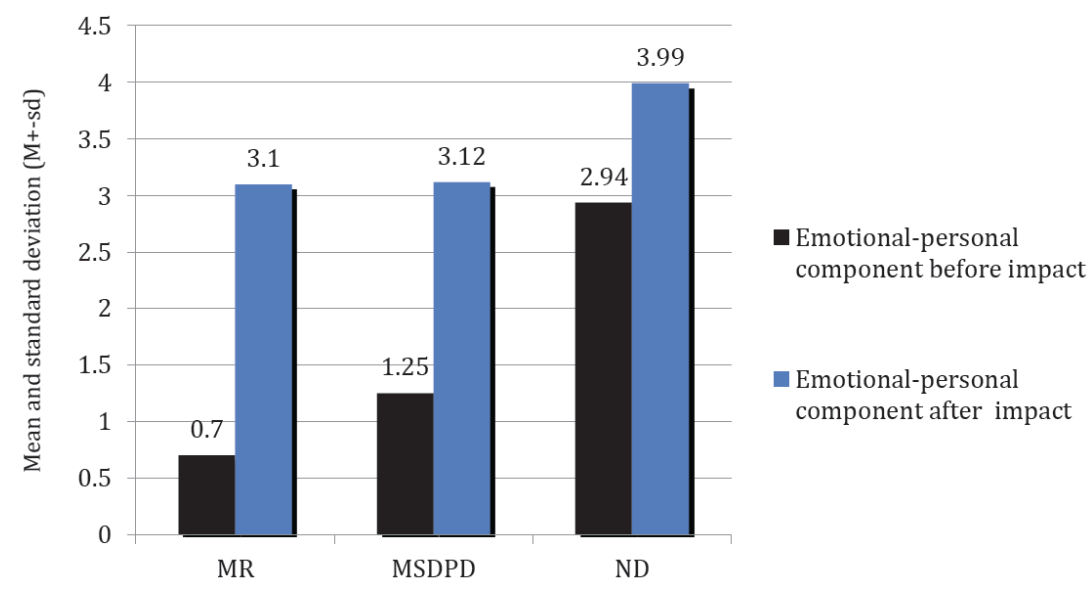

Figure 10: Dynamics of changes in the emotional-personal component in the studied groups.

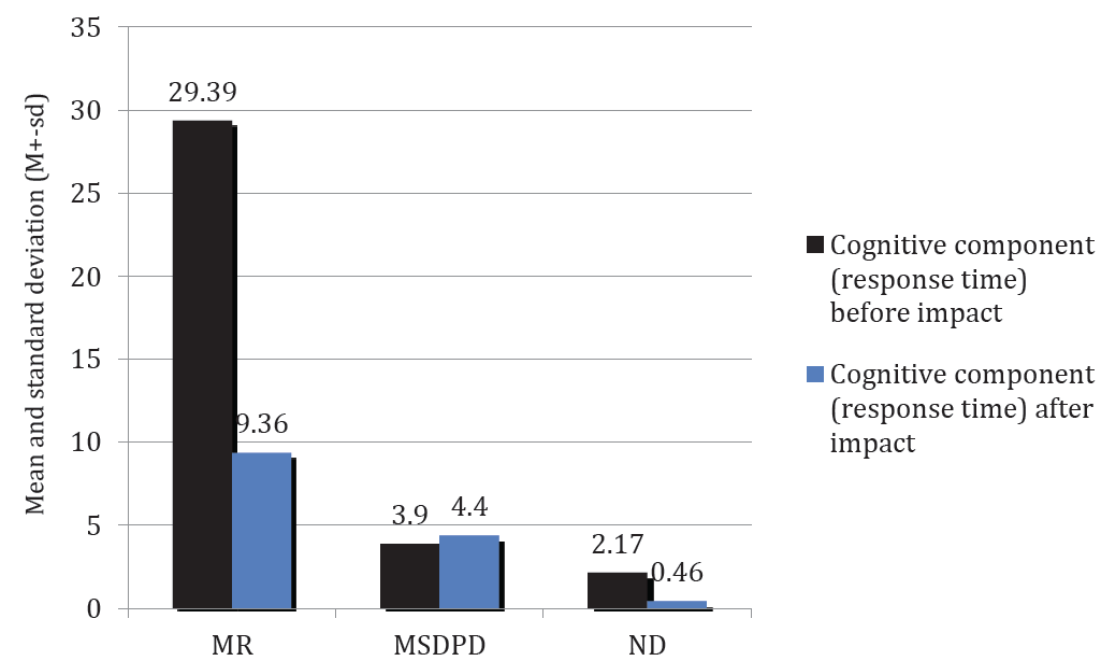

Figure 11: Dynamics of changes in the cognitive component.

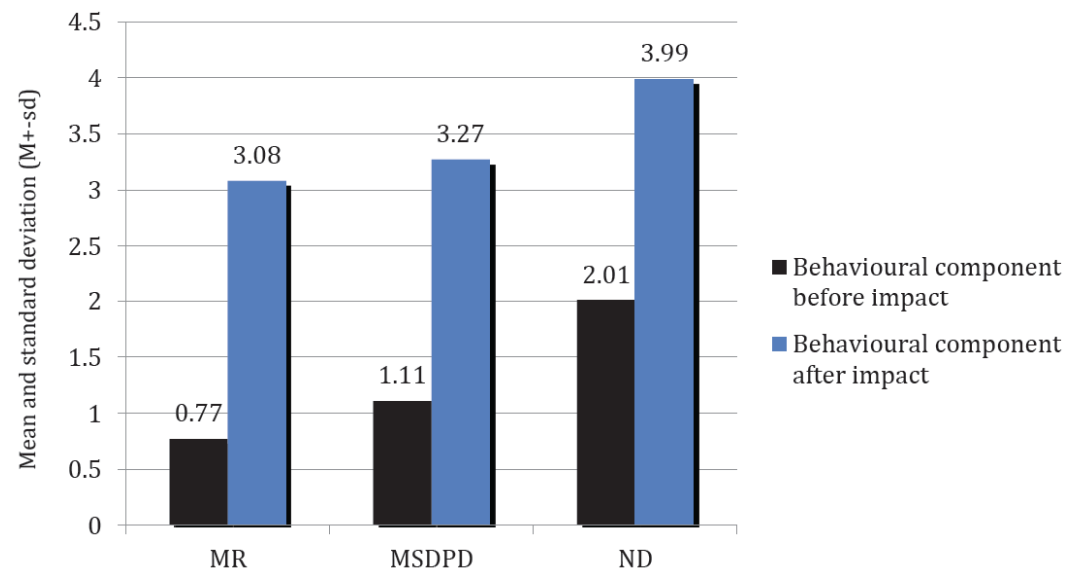

Figure 12: Dynamics of changes in the behavioural component.

difference does not reach the level of statistical significance.

The level of development of the behavioural component of non-verbal communication increased in all groups. The quality of answers in the group with mild mental retardation improved 4 times, in the group of mixed specific disorders of psychological development -3 times, in the group of normatively developing children -2 times (see Figure 12). In 
Table 9: Dynamics of Changes in the Groups' Understudy

\begin{tabular}{|c|c|c|c|}
\hline Component & $\begin{array}{l}\text { Group } 1(M R) \\
(M \pm s d)\end{array}$ & 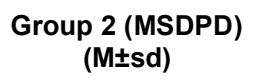 & $\begin{array}{c}\text { Group } 3 \text { (ND) } \\
(\mathrm{M} \pm \mathrm{sd})\end{array}$ \\
\hline Emotional-personal component before impact & $0.7 \pm 0.84$ & $1.25 \pm 0.74$ & $2.94 \pm 0.84$ \\
\hline Emotional-personal component after impact & $3.1 \pm 1.22^{*}$ & $3.12 \pm 0.83^{*}$ & $3.99 \pm 0.03^{*}$ \\
\hline Cognitive component before impact (response time) & $29.39 \pm 21.81$ & $3.9 \pm 3.98$ & $2.17 \pm 1.87$ \\
\hline Cognitive component after impact (response time) & $9.36 \pm 14.66^{*}$ & $4.33 \pm 5.75$ & $0.46 \pm 0.66^{*}$ \\
\hline Behavioural component before impact & $0.77 \pm 1.21$ & $1.11 \pm 1.23$ & $2.01 \pm 1.24$ \\
\hline Behavioural component after impact & $3.08 \pm 1.36^{*}$ & $3.27 \pm 0.81^{*}$ & $3.99 \pm 0.08^{*}$ \\
\hline
\end{tabular}

Notes: * - differences are statistically significant $(p<0.05)$ before and after psychological impact.

general, the dynamics of changes in the levels of development of the considered components of nonverbal communication in the groups of the surveyed are presented in Table $\mathbf{9}$.

Thus, the psychological impact significantly ( $p$ $<0.05)$ improved the main components of non-verbal communication (emotional-personal, cognitive, behavioural) in all groups, except for the cognitive component in the group of children with mixed specific disorders of psychological development in which there is no change. The best positive dynamics is noted in the group of children with mild mental retardation, which is due to the fact that these children had practically no understanding of what communication is in situations. Therefore, purposeful work on these aspects of non-verbal communication in a team in such children turned out to be quite effective.

The lack of positive dynamics in the group of subjects with mixed specific disorders of mental development in terms of the response time is associated with both their characteristic fatigue as a whole and with other reasons related to the child's subjective perception of the situation of the experimental psychological study. Because even children of the group with mild mental retardation, for whom severe fatigue is also typical, demonstrated positive dynamics. The results of a comparative analysis of groups by the level of development of the studied indicators after psychological impact are presented in Table 10.

After the psychological impact, the level of expression of the main components of non-verbal communication in the continuum from mild mental retardation to the normative level of intellectual development remained. Children with a normative level of intelligence development have statistically $(p<0.017)$ higher indices in all components of non-verbal communication compared to groups of children with mild mental retardation and with mixed specific disorders of psychological development. In addition to that, the groups of children with mild mental retardation and with mixed specific disorders of mental development do not differ statistically ( $p>0.017$ ), which can be explained by the similar level of intellectual development in both groups of children, considering, different dynamics of development and prognosis.

Table 10: Comparative Characteristics of the Components of Non-Verbal Communication in Children after Psychological Impact

\begin{tabular}{|c|c|c|c|}
\hline & 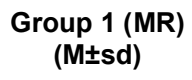 & $\begin{array}{c}\text { Group } 2 \text { (MSDPD) } \\
\text { (MIsd) }\end{array}$ & $\begin{array}{c}\text { Group } 3 \text { (ND) } \\
(\mathrm{M} \pm \mathrm{sd})\end{array}$ \\
\hline Emotional-personal component & $3.1 \pm 1.22$ & $3.12 \pm 0.83^{\star *}$ & $3.99 \pm 0.03^{* * *}$ \\
\hline Cognitive component & $9.36 \pm 14.66$ & $4.33 \pm 5.75^{\star *}$ & $0.46 \pm 0.66^{\star * *}$ \\
\hline Understanding spatial relationships & $2.98 \pm 1.3$ & $3.35 \pm 0.8^{\star *}$ & $3.93 \pm 0.25^{* * *}$ \\
\hline Behavioural component & $3.08 \pm 1.36$ & $3.27 \pm 0.81^{* *}$ & $3.99 \pm 0.08^{* * *}$ \\
\hline
\end{tabular}

Notes: * - statistically significant differences in groups 1 and $2(p<0.017)$.

${ }^{* *}$ - statistically significant differences in groups 2 and $3(p<0.017)$.

*** — statistically significant differences in groups 1 and $3(p<0.017)$ 


\section{DISCUSSION}

Non-verbal communication in children with intellectual disabilities is an understudied issue in scientific literature. However, some researchers consider the importance of non-verbal communication and the possibilities for its study. Do gestures pave the way? A systematic review of the transitional role of gesture during the acquisition of early lexical and syntactic milestones in young children with Down syndrome, the authors consider communication problems in children with Down syndrome. The authors note that problems with expressive speech are common in children with Down syndrome. For normally developing children, gestures play an important part in supporting the transition from monosyllabic to two-word statements. The authors also noted that there is no review of the role of gestures in supporting the development of expressive speech in children with Down syndrome. This systematic review aims to synthesise the current state of empirical evidence on the role of gestures during the acquisition of early lexical and syntactic skills in young children with Down syndrome. A systematic literature search was performed with the use of Pubmed, Scopus, PsycINFO, and Web of Science databases. A total of 12 studies met the inclusion criteria. The results of the study indicated that children with Down syndrome exhibit the same gestures and go through the same early stages of expressive speech development as children with normal intellectual development. However, in children with Down syndrome, developmental stages lag significantly, and, most importantly, the stage of additional combinations of gestures and words is rarely observed. Incorporating verbal communication and gestures into everyday communication between a child with Down syndrome and its parent can facilitate the child's transition from monosyllabic to two-word statements. The authors emphasise the need to include such activities in early language intervention programmes [12].

The following article investigates delays in speech development in young children. The authors note that delays in speech development increase the risk of autism spectrum disorders. The purpose of the study was to investigate the two types of gestures, such as deictic gestures and traditional gestures. The results indicated that early speech retardation is associated with a reduction in deictic and traditional gestures in the observation context. It is important to note that the use of deictic gestures was associated with the development of expressive speech in children with and without delayed speech. Deictic gestures play an important part in the development of expressive speech in babies, including those with delayed speech development. The authors note that directly determining the type and function of gestures in early intervention can be important in facilitating the development of speech skills in children [13].

The next study discusses speech pathologies in children who have certain deviations. The authors review the Strategic Plan for the American Speech and Hearing Association, The Path to Excellence. This study attempts to bridge the gap by redefining the panoptic view that most children who have speech delays "catch up" with their peers. The authors also note that one should not overlook children who still have a speech disorder. Late development of language skills can affect children's socialisation and school readiness and may put some children at risk of life-long disability. The early intervention programme has an established infrastructure. The parental intervention aims to eliminate risks and maximise protective factors [14].

This study reviews some of the research-developed early intervention models that have been applied and tested in real-life preschool programmes. In this study, educators implemented a modular social communication intervention, JASPER, into their curriculum. Sixty-six preschool children with autism from twelve grades were selected for immediate education. For children, indicators of major deficits (initiation of joint interaction, joint attention and language gestures, play skills) and standardised cognitive indicators were improved. Teachers conducted evidence-based interventions with significant reductions in significant deficits in children with intellectual disabilities [15].

\section{CONCLUSIONS}

Data of the study showed that, depending on the level of intelligence or, more precisely, on the diagnosis given to the child, there are differences in the dynamics of development of components of non-verbal communication. Children with mild mental retardation display lower results than children with mixed specific disorders of psychological development and children with a normative level of intellectual development. Evaluation of the dynamics of changes demonstrates that children with mild mental retardation improve their performance with a comparatively higher intensity than children from other groups. 
Intellectual underdevelopment in children with clinical diagnosis $\mathrm{F} 70$ - mild mental retardation becomes a determinant of a decrease in the indicators of the cognitive component of non-verbal communication. In turn, the development of the behavioural and emotional-personal components of non-verbal communication acts as a means of compensating for the existing violation. According to the data of empirical research and expert assessments of teachers and parents, the proposed programme of psychological influence aimed both at the development of these components of non-verbal communication, and at activating the compensatory capabilities of children, allows them to interact with their social environment more successfully. It is important to note that the system for assessing the components of nonverbal communication developed in the course of the study also demonstrates its effectiveness in diagnosing and assessing the characteristics of non-verbal communication in children.

Thus, it is important to note that children of primary school age with mild mental retardation significantly differ from normatively developing peers in their characteristics of the development of non-verbal communication, as well as from peers with mixed specific disorders of psychological development. Decreased intelligence makes it difficult to understand, recognise, and use various means of communication. The purposeful psychological impact, focused on the development of all aspects of non-verbal communication, based on the specific ability to use conventional gestures associated with the representation of another person of their emotional state, as well as aimed at activating social, behavioural reactions, helped to improve the communication skills of primary school children with varying degrees of intelligence decline.

\section{ACKNOWLEDGEMENTS}

None.

\section{REFERENCES}

[1] Zashchirinskaia OV. Clinical and psychological aspect of communicative and personal development of children with mental retardation. Petersburg Psychological Journal 2013; 2: 1-14.
[5] Knapp M. Nonverbal communication in human interaction. Boston: Cengage Learning, 2013.

[6] Upreti R, Singh R. Impact of Social Class on the Behavioural Skills of Mentally Challenged Children. Journal of Human Ecology 2016; 53(1): 65-73. https://doi.org/10.1080/09709274.2016.11906957

[7] Hronis A, Roberts L, Kneebone II. A review of cognitive impairments in children with intellectual disabilities: Implications for cognitive behaviour therapy. British Journal of Clinical Psychology 2017; 56(2): 189-207. https://doi.org/10.1111/bjc.12133

[8] Rodas NV, Zeedyk SM, Baker BL. Unsupportive parenting and internalising behaviour problems in children with or without intellectual disability. Journal of Intellectual Disability Research 2016; 60 (12):1200-1211. https://doi.org/10.1111/jir.12332

[9] Dimitrova N, Ozcaliskan S, Adamson LB. Parents' translations of child gesture facilitate word learning in children with Autism, Down Syndrome and typical development. Journal of Autism and Developmental Disorders 2016; 46(1): 221-231. https://doi.org/10.1007/s10803-015-2566-7

[10] Westerinen $\mathrm{H}$, Kaski M, Virta LJ, Kautiainen $\mathrm{H}$. The nationwide register-based prevalence of intellectual disability during childhood and adolescence. Journal of Intellectual Disability Research 2017; 61: 802-809. https://doi.org/10.1111/jir.12351

[11] Yankova Z. Assistive devices and technology in education of children and students with mental retardation. Trakia Journal of Sciences 2010; 8(3): 273-277.

[12] Te Kaat- van den Os DJ, Jongmans MJ, Volman MJM Lauteslager PE. Do gestures pave the way? A systematic review of the transitional role of gesture during the acquisition of early lexical and syntactic milestones in young children with Down syndrome. Child Language Teaching and Therapy 2014; 31(1): 71-84.

https://doi.org/10.1177/0265659014537842

[13] Manwaring SS, Swineford L, Mead DL, Yeh C-C, Zhang Y, Thurm $A$. The gesture-language association over time in toddlers with and without language delays. Autism \& Developmental Language Impairments 2019. https://doi.org/10.1177/2396941519845545

[14] Capone Singleton N. Late talkers: Why the wait-and-see approach is outdated. Pediatric Clinics of North America 2018; 65(1): 13-29.

https://doi.org/10.1016/i.pcl.2017.08.018

Chang Y-C, Shire SY, Shih W, Gelfand C, Kasari C. Preschool Deployment of Evidence-Based Social Communication Intervention: JASPER in the Classroom. Journal of Autism and Developmental Disorders 2016; 46(6): 2211-2223. https://doi.org/10.1007/s10803-016-2752-2

(c) 2020 Oksana V. Zashchirinskaia; Licensee Lifescience Global.

This is an open access article licensed under the terms of the Creative Commons Attribution Non-Commercial License (http://creativecommons.org/licenses/by-nc/3.0/) which permits unrestricted, non-commercial use, distribution and reproduction in any medium, provided the work is properly cited. 